\title{
O Uso de Dispositivos de Segurança Alternativos para Reduzir Acidentes de Trabalho na Operação com Serras nas Indústrias Madeireiras
}

\author{
Clovis Eduardo Nunes Hegedus ${ }^{1}$, Rômulo Maziero², \\ Vinicius Peixoto Tinti ${ }^{2}$, Wendel Pianca Demuner ${ }^{2}$ \\ ${ }^{1}$ Departamento de Engenharia Florestal, Universidade Federal do Espírito Santo - UFES \\ ${ }^{2}$ Engenharia Industrial Madeireira, Universidade Federal do Espírito Santo - UFES
}

\begin{abstract}
RESUMO
Os cuidados necessários para o manuseio de serra circular e serra destopadeira são indispensáveis para a redução de acidentes e maior ganho em produtividade. Pensando nesta questão, o trabalho desenvolvido propôs pesquisar, testar e comparar formas rápidas e baratas que permitam adaptar dispositivos que evitem acidentes sem reduzir a produtividade, requisito básico para o aumento do bem-estar do indivíduo e aumento da competitividade da empresa. Entretanto, a atividade de operação de equipamentos industriais, como serras, típicas do segmento, tem mostrado uma face terrível, ao ser um dos principais contribuintes para a incapacitação de muitos trabalhadores, seja pela perda de horas trabalhadas, seja pela real amputação de partes dos membros humanos superiores. O estudo focaliza os municípios do entorno de Jerônimo Monteiro-ES, inclusive com a comparação dos índices existentes na região em relação a números relatados em pesquisas realizadas em outros Estados da Federação.
\end{abstract}

Palavras-chave: serra circular, serra destopadeira, acidentes de trabalho.

\section{The Use of Alternative Safety Devices to Reduce Accidents in Industrial Logging Operation in the Mountains}

\begin{abstract}
The caution required for handling crosscut saws and circular saws are indispensable for the reduction of accidents and higher productivity gains, For this, the purpose of this study was to research, test and compare inexpensive and quick ways to adapt and enable devices in order to prevent accidents, with no productivity reduction - a basic requirement for increasing competitiveness and the well being of individuals. Nevertheless, the activity of operating industrial equipment typical of this segment, such as saws, has shown a terrible side; it is a major contributor to the physical disablement of many workers, either due to the loss of working hours, or the amputation of upper limbs. This study focuses on the municipalities surronding Jeronimo Monteiro, State of Espirito Santo, Brazil; including the comparison of regional indices to figures reported in studies conducted in other states.
\end{abstract}

Keywords: circular saw, crosscut saws, work injuries. 


\section{INTRODUÇÃO}

A área definida pela Classificação Nacional de Atividades Econômicas - CNAE (Comissão..., 2009) para a atividade de 16.10-2 - Desdobramento da Madeira; 16.22 - Fabricação de Estruturas de Madeira; 16.23 - Embalagens de Madeira; 16.29 - Fabricação de artefatos de madeira, e 31.01-2 - Fabricação de móveis com predominância da madeira apresenta no relatório 2006/2007 um alto índice de acidentes nesta área, inclusive com acréscimo de aproximadamente $20 \%$ de um ano para outro (Brasil, 2008).

Sabe-se que as principais responsáveis por acidentes, com lesões permanentes com perdas de dedos e mãos, são duas das mais comuns máquinas utilizadas no processo de desdobro e processamento da madeira: a serra circular e a serra destopadeira. Estudo feito entre 1998 e 2001 pela Secretaria da Saúde do Estado do Paraná mostra que a indústria da madeira é a que alcançou o maior número de acidentes com amputações no período, destacandose a serra circular, responsável por $15 \%$ de todas as amputações registradas (Araújo \& Salgado, 2002). Fiedler et al. (2001) corroboram a leitura feita, em relação a marcenarias no Distrito Federal. A percepção mostrada sobre o tema levanta a preocupação na condução de um estudo mais aprofundado sobre a proposição de dispositivos simples, que evitem ou reduzam de maneira significativa as causas dos acidentes de trabalho ocorridos nas pequenas e médias empresas do setor de processamento da madeira no entorno de Jerônimo Monteiro-ES.

$\mathrm{O}$ projeto levantou as empresas processadoras da madeira na região e, em seguida, quantificou os acidentes, suas consequências e seus impactos; buscou ainda compreender como o acidente ocorre nas empresas inicialmente identificadas e acompanhou os métodos utilizados na operação desses dois tipos de serras, procurando propor e testar formas simples de solução quanto à segurança da operação, sem perda de produtividade.

\section{MATERIAL E MÉTODOS}

A pesquisa foi baseada em um levantamento inicial da população de empresas de processamento da madeira, como também dos índices de acidentes com amputações nessas indústrias. Seguiu-se a confecção de dispositivos empregados nas serras utilizadas da região do entorno de Jerônimo Monteiro-ES.

Inicialmente, procurou-se identificar dados primários sobre acidentes levantados por diversos órgãos públicos, como prefeituras, estado, etc. e associações, como sindicatos. Notou-se a completa ausência de tais estudos, impossibilitando o levantamento desses dados em órgãos oficiais. Assim, o trabalho passou a uma segunda etapa, que foi dividida em duas fases distintas: elaboração de um questionário e sua respectiva validação, seguida de seleção de empresas para um aprofundamento no estudo do problema. Em seguida, foram aplicados os questionários a 19 trabalhadores de maneira individualizada, o que foi realizado entre maio e junho de 2010. Foram exploradas questões sobre as características da função, bem como hábitos, costumes e vícios, treinamento, equipamentos de proteção individual (EPIs) e segurança das máquinas. Nenhum trabalhador recusou-se a responder o questionário.

A fabricação dos dispositivos alternativos foi conduzida no Laboratório de Ciência da Madeira do Núcleo de Estudos e de Difusão de Tecnologia em Floresta, Recursos Hídricos e Agricultura Sustentável (NEDTEC), do Centro de Ciências Agrárias da Universidade Federal do Espírito Santo (CCA-UFES), localizado no município de Jerônimo Monteiro, sul do Espírito Santo, no período de janeiro a junho de 2010.

As máquinas envolvidas no estudo foram serras circulares e serras destopadeiras, e todo o processo de implementação dos dispositivos constou das seguintes etapas:

a) escolha da espécie de madeira (Eucalyptus grandis); e

b) escolha do tipo de serra circular e serra destopadeira, para implantação do dispositivo de segurança a ser testado e analisado.

Seguem-se as etapas de fabricação e montagem dos dispositivos nas Serras circulares (modelo: SCI-25) e Serras destopadeiras (modelo: DT-600):

a) preparar as peças de madeira, conforme as dimensões de mesa da máquina: quatro peças com $55 \times 550 \mathrm{~mm}$, duas peças com $55 \times 935 \mathrm{~mm}$, quatro peças com $55 \times 600 \mathrm{~mm}$ e duas peças com $55 \times 1090 \mathrm{~mm}$; 
b) encaixar as peças, formando dois esquadros retangulares que ficarão sobre a mesa da máquina;

c) preparar sete peças com $55 \times 300 \mathrm{~mm}$;

d) fazer um rasgo com broca de $5 / 16$ " nas peças com dimensões $55 \times 300 \mathrm{~mm}$;

e) utilizar pregos e/ou parafusos de 1/4" para fixação das peças menores nos esquadros retangulares;

f) utilizar tela metálica para cobrir todo o dispositivo, evitando que a projeção de pedaços de madeira ou dentes do disco atinjam o operador; e

g) acrescentar, na parte inferior do esquadro retangular, uma pequena fita de borracha (aproveitar pneus velhos), evitando deste modo o retrocesso da peça a cortar e o contato direto das mãos com os dentes do disco.

\section{RESULTADOS E DISCUSSÃO}

Foram avaliadas oito empresas, sete marcenarias e apenas uma serraria. Esta última realiza tanto o processo de desdobro primário da tora quanto o desdobro secundário das peças; as marcenarias, apenas o desdobro secundário. Em todas as empresas, os marceneiros desempenham várias funções na linha de produção e os próprios donos exercem a atividade de marceneiro, sendo que em apenas uma delas o dono não exerce tal função.

O número de funcionários variou de um a quatro, todos do gênero masculino, sendo que das oito empresas, três delas possuem quatro funcionários cada $(37,5 \%)$, outras três possuem um funcionário cada $(37,5 \%)$ e apenas duas possuem dois funcionários cada (25\%), totalizando 19 marceneiros. Três empresas podem ser classificadas como individuais, ou seja, apenas o dono trabalha, sendo que destas, duas não estão mais em operação, pois os donos atualmente estão aposentados.

A idade dos marceneiros variou de 22 a 60 anos, sendo que apenas um entrevistado apresentou idade superior a 60 anos, tendo 70 anos (atualmente aposentado). A idade predominante está entre 56 e 60 anos - cinco entrevistados (26,3\%) - e entre 46 e 50 anos - quatro entrevistados $(21,1 \%)$.

O tempo de profissão dos trabalhadores variou de um ano até acima de 40 anos, sendo que as faixas mais significativas se concentraram entre 26 e 30 anos - três marceneiros (15,8\%) - e entre 36 e 40 anos, também com três marceneiros
$(15,8 \%)$. A maioria não possui treinamento, tendo aprendido a profissão no próprio local de trabalho: 14 entrevistados (73,7\%), como ajudante de marceneiro. Entre os entrevistados, 21,1\% afirmaram fazer o uso de cigarro e $47,4 \%$ fazem o uso de bebidas alcoólicas, somente após o expediente.

Foram entrevistados 19 funcionários; quando perguntados se teriam sofrido acidentes na marcenaria ou serraria em que trabalham ou trabalharam, oito responderam sim e 11 responderam que não. Perguntados se a empresa disponibilizava EPIs (Figura 1), uma grande maioria afirmou que isto ocorria. Entretanto, surpreendendo os entrevistadores, um percentual maior entre os que recebem o equipamento relatou não os utilizar (Figura 2). Isso, infelizmente, retrata a realidade dos trabalhadores: a maioria não usa EPIs e até os evita.

Quando os entrevistados foram questionados se já sofreram acidentes na marcenaria ou serraria em que trabalhavam, oito responderam sim e 11 responderam que não (Figura 3). A maioria dos entrevistados $(84,2 \%)$ só trabalhou na região, que engloba Jerônimo Monteiro e Alegre-ES; apenas

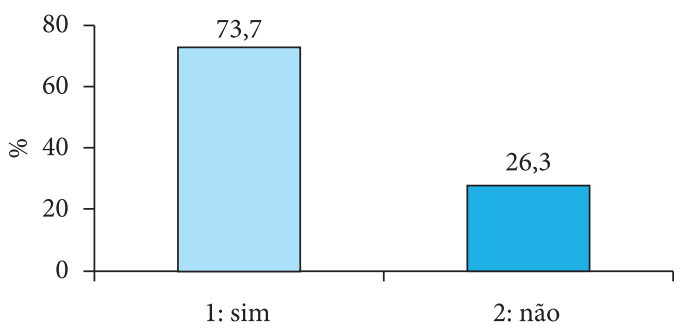

Figura 1. Disponibilização de EPI’s pelas empresas. Figure 1. Provision of PPE by employers.

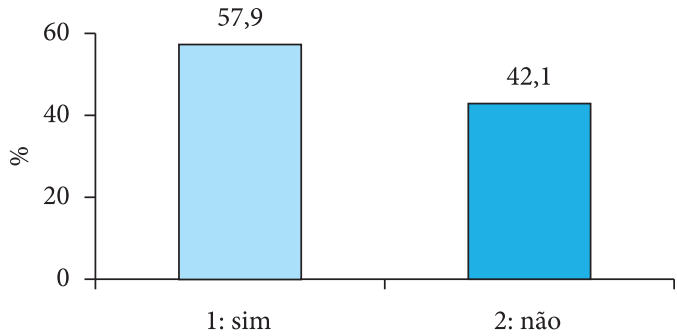

Figura 2. Uso de EPI's pelo empregado. Figure 2. Use of PPE by the employee. 
$15,8 \%$ trabalharam em outra região e não relataram que sofreram acidentes nesses locais.

Em relação à máquina ou ferramenta que o entrevistado considerava mais perigosa, a resposta foi que a grande vilã seria a tupia. Apenas um entrevistado não opinou, pois é ajudante e não manuseia máquinas, totalizando 18 respostas (Tabela 1).

Não se pode acusar que os problemas sejam decorrentes de inexistência de manutenção ou manutenção inadequada nas máquinas, conforme se constata nas Figuras 4 e 5.

Como relatado, na medida em que não foram identificados registros pelos órgãos competentes de dados de acidentes no segmento de beneficiamento primário ou secundário da madeira na região, entendeu-se que uma confiável fonte de dados seriam os relatos de trabalhadores para o levantamento de tais dados. Foram perguntados quantos acidentes os entrevistados haviam presenciado nos últimos tempos. Para minimizar a possibilidade de contagem em duplicidade de relatos, nomes, locais e tipo de acidentes presenciados ou experimentados foram anotados no questionário. Com tais cuidados para não tabular acidentes repetidos, foi feita a contagem segundo os relatos dos trabalhadores.

Nas entrevistas, foram notificados 32 acidentes ocorridos na região de Jerônimo Monteiro e AlegreES nos últimos anos, um número considerado grande se comparado ao número de funcionários entrevistados, perfazendo-se praticamente 1,7 acidentes por trabalhador. Ressalte-se que muitos dos acidentados não exercem mais a função. No que se refere à gravidade dos acidentes, os entrevistados forneceram as respostas listadas na Tabela 2.

Os entrevistados foram ainda questionados sobre quais seriam as condições ou abordagens a serem tomadas de maneira a evitar ou reduzir acidentes nas operações de serra e tupia, além das outras máquinas disponíveis nas serrarias e marcenarias. $\mathrm{O}$ resultado pode ser visto na Tabela 3.

Deve-se atentar para o fato de que, apesar de todos responderem que a manutenção das máquinas era feita, dois entrevistados apontaram a necessidade de ter máquinas em bom estado de conservação.
De acordo com os resultados, a maioria dos trabalhadores mostra que tem limitações técnicas, o que explica, em parte, os acidentes identificados como consequência do despreparo na execução de

Tabela 1. Máquinas consideradas perigosas.

Table 1. Machines considered dangerous.

\section{Máquinas}

Valores médios (\%)

\begin{tabular}{lr} 
Tupia & 77,8 \\
Desempenadeira & 5,6 \\
Tupia e desempenadeira & 11,1 \\
Serra Circular & 5,6 \\
\hline
\end{tabular}

Tabela 2. Gravidade dos acidentes.

Table 2. Severity of accidents.

\begin{tabular}{lcc}
\multicolumn{1}{c}{$\begin{array}{c}\text { Gravidade dos } \\
\text { acidentes }\end{array}$} & Valores & $\begin{array}{c}\text { Valores } \\
\text { médios (\%) }\end{array}$ \\
\hline Morte & 0 & 0 \\
Afastamento definitivo & 1 & 1,7 \\
Afastamento maior que 15 dias & 32 & 55,2 \\
Perda ou lesão grave dos dedos & 24 & 41,4 \\
Perda ou lesão grave da mão & 1 & 1,7 \\
\hline
\end{tabular}

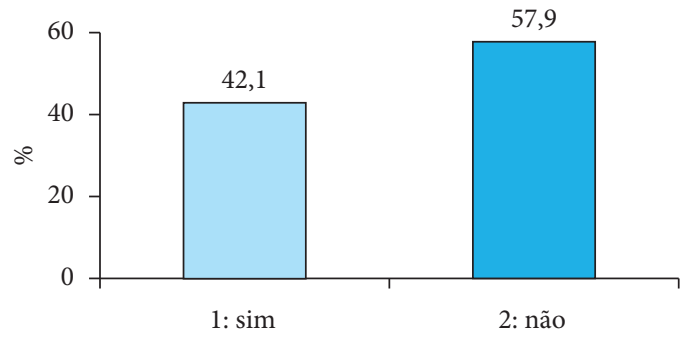

Figura 3. Acidentes sofridos pelos entrevistados. Figure 3. Accidents suffered by respondents.

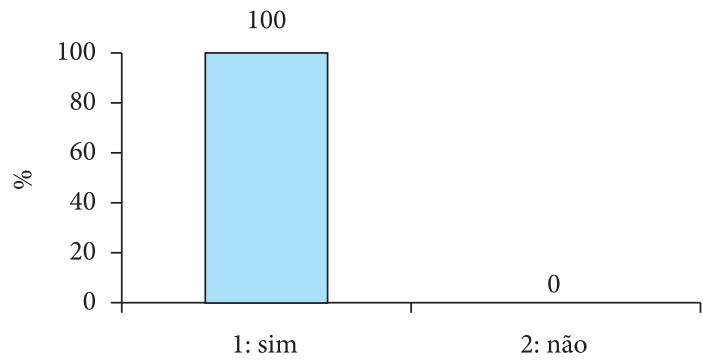

Figura 4. Estado de conservação das ferramentas é adequado.

Figure 4. Adequate conservation of equipment. 


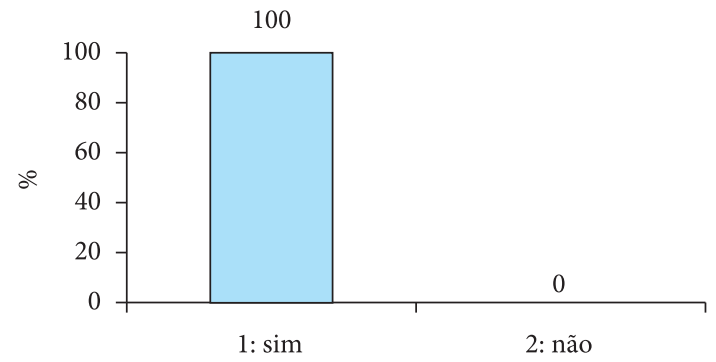

Figura 5. Manutenção das máquinas (afiação) é feita regularmente.

Figure 5. Maintenance of machines (grinding) is done regularly.

Tabela 3. Opinião dos trabalhadores para melhoria das condições de segurança do trabalho na área.

Table 3. Opinion of the workers for improvement of safety in the work area.

\begin{tabular}{|lcc|}
\multicolumn{1}{c}{$\begin{array}{c}\text { Opinião dos } \\
\text { trabalhadores }\end{array}$} & $\begin{array}{c}\text { Respostas } \\
\text { anotadas }^{*}\end{array}$ & $\begin{array}{c}\text { Valores } \\
\text { médios (\%) }\end{array}$ \\
\hline Atenção do funcionário & 10 & 34,5 \\
\hline Treinamento do funcionário & 6 & 20,7 \\
\hline Modernizar as máquinas & 5 & 17,2 \\
\hline Usar EPIs & 3 & 10,3 \\
\hline Máquinas em bom estado & 2 & 6,9 \\
\hline Protetor de serras & 1 & 3,4 \\
\hline Exaustores & 1 & 3,4 \\
\hline Calma na execução da atividade & 1 & 3,4 \\
\hline Utilizar equipamento adequado & 1 & 3,4 \\
\hline Melhor fixação das peças & 1 & 3,4 \\
\hline Local livre & 1 & 3,4 \\
\hline
\end{tabular}

${ }^{\star} \mathrm{O}$ entrevistado podia apontar mais de um fato.

determinada tarefa de maneira correta. Segundo Murrel (1965); Zócchio (1971); Iida (1990), apud Debiasi (2002), este conhecimento depende principalmente do treinamento recebido pelo trabalhador, bem como a experiência acumulada durante a execução da atividade.

O nível de escolaridade também influencia o nível técnico do trabalhador. Segundo Zócchio (1971), apud Debiasi (2002), trabalhadores com maior nível de escolaridade apresentam maior facilidade para compreender as medidas de segurança e de se conscientizar da importância das mesmas. Como a maioria dos entrevistados apresenta ensino médio completo (42,1\%), a não utilização de EPIs é um risco assumido de maneira consciente pelos trabalhadores e, infelizmente, tal utilização não é devidamente exigida pelas empresas.

Segundo o chefe do setor de Medicina e Segurança do Trabalho da Delegacia Regional do Trabalho do Paraná, Sérgio Barros (2002), apud Carvalho (2008), a informalidade é motivo de preocupação no setor madeireiro. Como observado no presente estudo, a maioria das marcenarias são de origem familiar, as máquinas são antigas, o excesso de barulho, o pó da serragem e os cavacos podem causar problemas respiratórios, de visão, de audição, sem contar as amputações. Isto tudo ainda é agravado pelos trabalhadores não possuírem um treinamento adequado.

O Ministério do Trabalho (2000), apud Carvalho (2008), aponta que 20 bilhões de reais são gastos com acidentes de trabalho por ano no Brasil, representando 2\% do Produto Interno Bruto (PIB). De acordo com Barros (2002), apud Carvalho (2008), é muito dinheiro gasto com acidentes, que poderia ser investido em outro âmbito. Se esta quantia for aplicada na prevenção, as empresas economizariam bastante; note-se que este investimento não pode ser visto como gasto. De acordo com Barros (2002), apud Carvalho (2008), se a empresa investir um real, em dois anos terá economizado cinco reais.

Além da proteção individual, a empresa tem de investir no ambiente de trabalho. Não basta fornecer máscaras, luvas, roupas especiais, protetores auriculares e óculos de segurança, pois a proteção contra os acidentes tem de ser realizada também no ambiente de trabalho.

A maioria dos trabalhadores considerou a tupia como a máquina mais perigosa $(77,8 \%)$ e, em segundo lugar, a tupia e a desempenadeira juntas (11,6\%). Isto se deve à falta de atenção do funcionário, tanto na tupia como na desempenadeira. Apontou-se, ainda, como máquina com grande versatilidade, apenas a tupia; por não apresentar proteção, apenas a tupia, $e$ por ter alta velocidade, a tupia e a desempenadeira.

Segundo Carvalho et al. (2009), o principal problema a ser resolvido na tupia é a diversidade de trabalhos que podem ser realizados por esta, o que obriga a utilização de vários protetores. Estes, em muitos casos, são de difícil colocação, motivo pelo qual acabam não sendo utilizados. Souza (2004) relata que os trabalhos realizados diretamente no eixo 
porta-ferramenta são mais perigosos se comparados com o trabalho da guia. As tupias oferecem os seguintes tipos de riscos: ruptura ou projeção de ferramenta de corte, contato com a ferramenta e retrocesso da peça trabalhada.

Os acidentes na tupia, de acordo com Carvalho et al. (2009), ocorrem tanto na zona de trabalho, como na parte posterior da guia. Nesta última, os acidentes são menos frequentes, por não existir proximidade das mãos durante o processo. A parte posterior deve estar coberta para evitar o contato do trabalhador com a ferramenta de corte. Para um trabalho correto na tupia, deve-se ocultar a ferramenta de corte, ou seja, trabalhar com a ferramenta de corte protegida.

$\mathrm{Na}$ desempenadeira, segundo Carvalho et al. (2009), os acidentes ocorrem pelo contato das mãos do operador com as lâminas de corte ou pelo retrocesso da peça que está sendo processada. O contato das mãos nas lâminas de corte pode ocorrer tanto na zona posterior como na parte anterior da guia de alimentação. A regra de proteção é cobrir a parte de lâmina de corte que não está sendo utilizada. Na parte posterior, deve-se utilizar uma proteção fixa; já na parte anterior, essa proteção deve ser autorregulável, para permitir a passagem da peça a ser trabalhada e esta voltar automaticamente à posição inicial sem a atuação do operador.

Já o retrocesso da peça ocorre pela existência de nós ou outros defeitos na madeira ou pelo aplainamento de peças muito curtas. Nesta situação, devem-se utilizar dispositivos que auxiliam o deslizamento da peça contra as lâminas de corte e, na primeira situação, eliminar madeiras com defeitos.

Segundo Silva et al. (2002), conhecer o perfil dos trabalhadores é de grande importância para o desenvolvimento de trabalhos referentes a treinamentos, orientações e intervenções no ambiente de trabalho. No treinamento, é de suma importância a identificação das características do trabalhador, como o grau de escolaridade e a experiência na profissão, para encontrar a melhor forma de se abordarem os temas durante o treinamento.

A satisfação no trabalho tem uma significativa importância, quando se quer introduzir novas ideias, pois permite melhor aceitação por parte dos trabalhadores em relação às mudanças, de acordo com os autores.

O presente trabalho apresentou algumas limitações quando da aplicação do questionário, pois maiores detalhamentos do público entrevistado poderiam ter sido explorados, como a caracterização do ambiente de trabalho, a caracterização das marcenarias, aprofundar-se mais no perfil do marceneiro, como, por exemplo, verificar a renda salarial média dos marceneiros, se todos possuem registro em carteira de trabalho, etc. Mas a inclusão de tais pontos, apesar de interessantes, poderia causar cansaço e descompromisso nas respostas dadas. Assim, optou-se pela simplificação do levantamento feito.

Perguntas outras podem ser úteis, tais como abordar se os trabalhadores apresentam algum problema de saúde, como alergia ao pó da madeira, aos produtos químicos utilizados, como cola para fórmica, vernizes e solventes. Outros pontos de interesse abarcariam qual o tempo de jornada de trabalho e se há pausas durante a jornada de trabalho, qual a frequência de ocorrência dessas pausas, etc.

Analisando os dados obtidos na operação sem e com o dispositivo de segurança instalado nos dois tipos de serras, fica comprovada a funcionalidade do mesmo, sem prejudicar o rendimento da produção. Submetendo-se aos testes de tempo versus número de passos dos dispositivos, é possível analisar o desempenho de cada operação.

Na Figura 6, é apresentado o comportamento de uma operação em serra circular sem e com dispositivo de segurança. É possível observar que uma máquina com dispositivo não altera a produção, tanto que o tempo de entrada e saída da madeira na serra circular apresenta um desvio padrão de 0,023 minuto com dispositivo e sem dispositivo de 0,021 minuto para um número de 30 passadas, conforme a Tabela 4.

$\mathrm{O}$ processo operacional da serra circular não sofreu alterações e comportou-se ajustável às formas de trabalho. O dispositivo de segurança apresentado na Figura 7 mostra que não há contato da mão do 


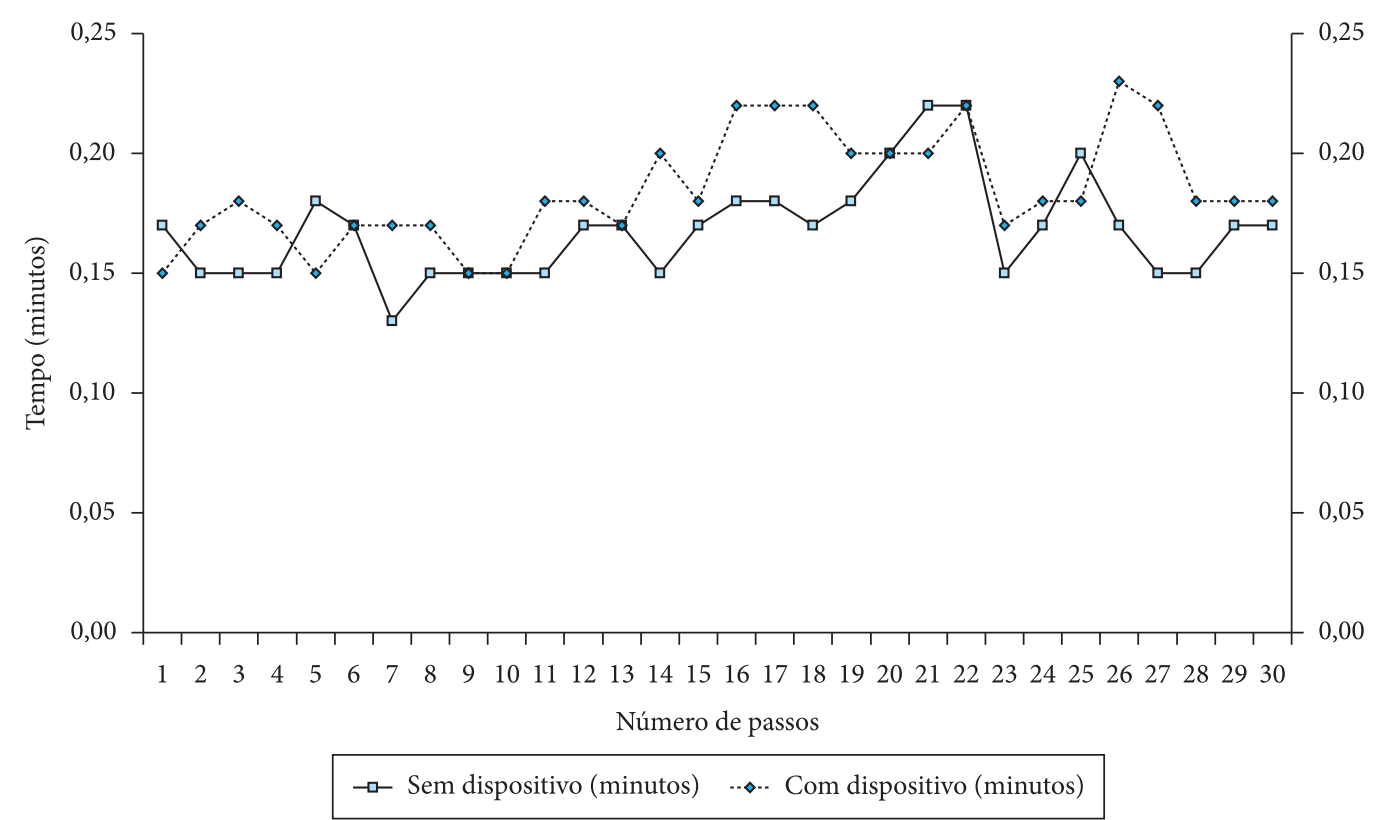

Figura 6. Tempo vs. número de passos.

Figure 6. Time vs. no. of steps.
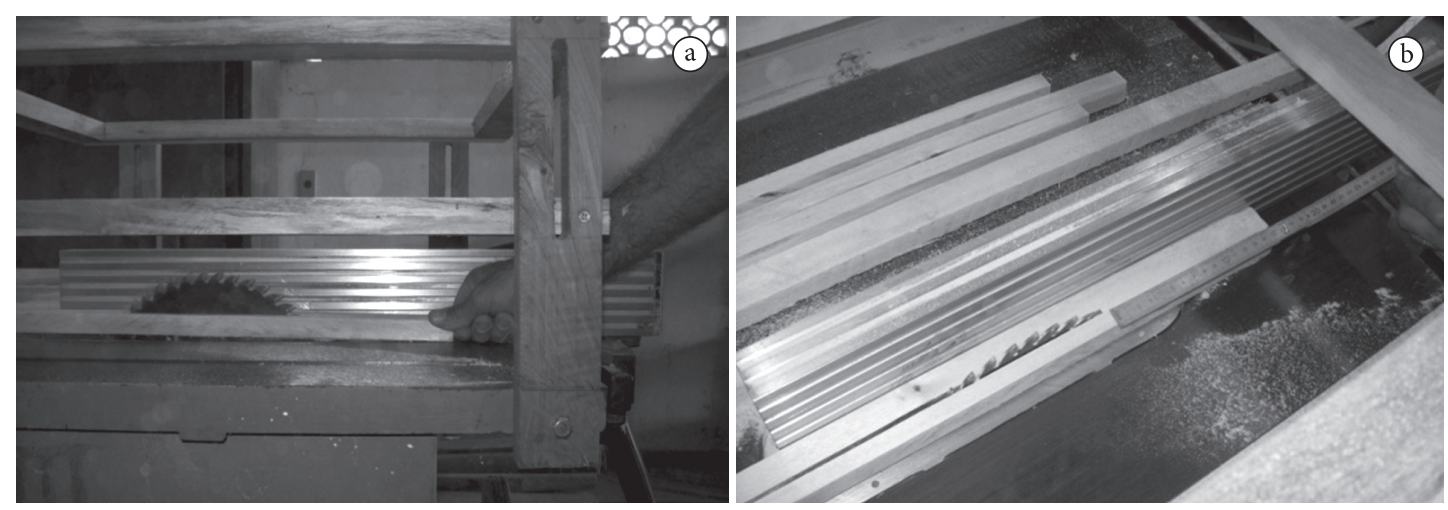

Figura 7. Serra circular com dispositivo de segurança instalado, mostrando a) vista lateral de uma peça de madeira sendo serrada com detalhe da disposição da mão do operador; e b) distância entre os dentes do disco e a mão do operador de $25 \mathrm{~cm}$, gerando uma área de segurança.

Figure 7. Circular saw with a safety device installed, showing a) side view of a piece of wood being sawed in detail the layout of operator's hand; and b) distance between the blade teeth and the hand of the operator of $25 \mathrm{~cm}, \mathrm{creating}$ an area security.

operador com os dentes do disco, logo se evitando possíveis mutilações.

Na Figura 8, é apresentado o comportamento de uma operação em serra destopadeira sem e com dispositivo de segurança. É possível observar que uma máquina com dispositivo não altera a produção, tanto que o tempo de entrada e saída da madeira na serra destopadeira possui um desvio padrão de 0,040 minuto com dispositivo e sem dispositivo de 0,034 minuto para um número de 30 passadas, conforme a Tabela 5 .

Assume-se que as diferenças das médias de tempo devem-se à influência das curvas de aprendizado na tarefa, consolidadas na operação tradicional e ainda em construção na tarefa com os dispositivos. 


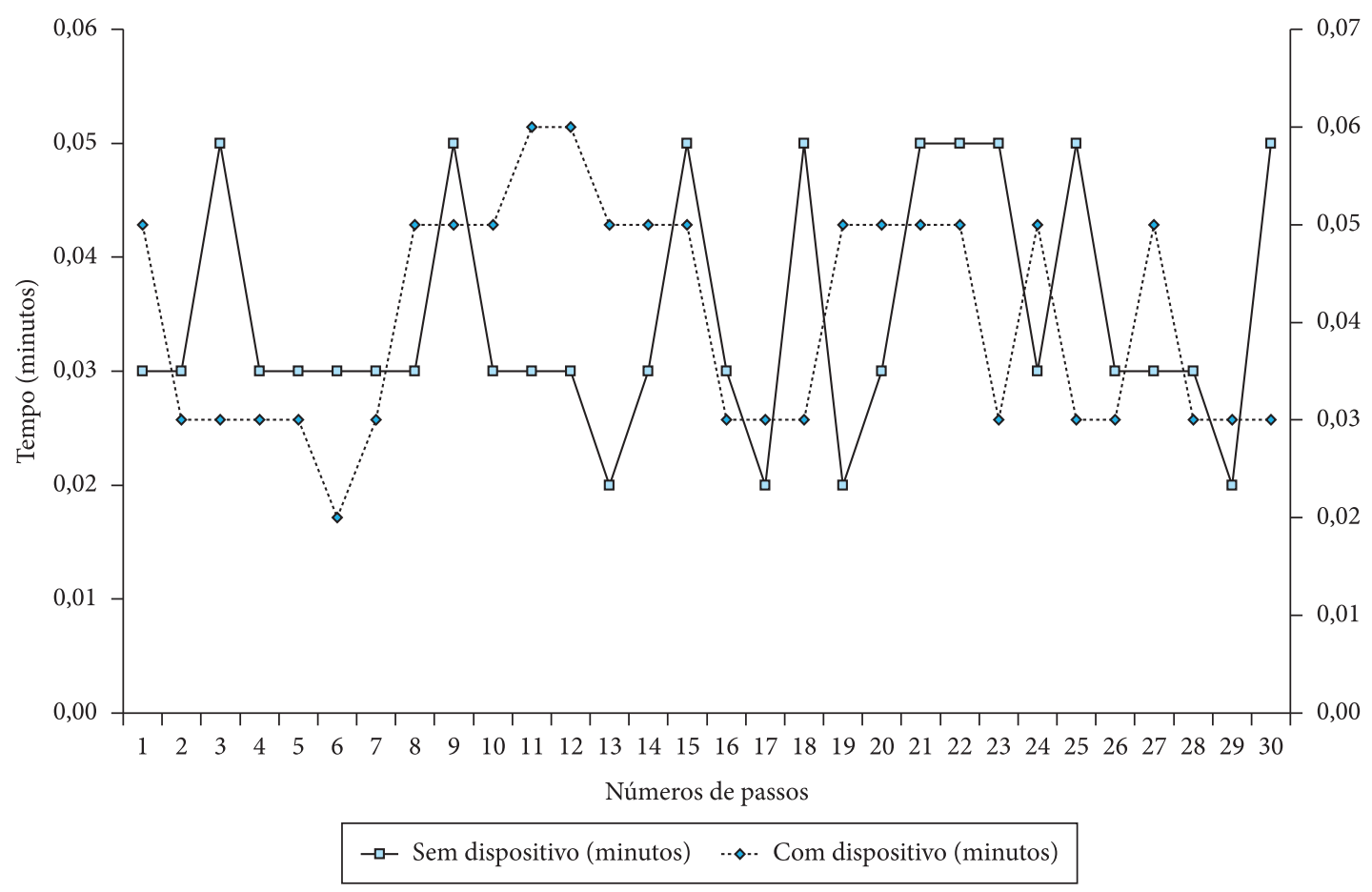

Figura 8. Tempo vs. número de passos.

Figure 8. Time vs. no. of steps.

Tabela 4. Média e desvio padrão.

Table 4. Average and standard deviation.

\begin{tabular}{lcc} 
Dispositivo & $\begin{array}{c}\text { Média } \\
(\%)\end{array}$ & $\begin{array}{c}\text { Desvio padrão } \\
\text { (minuto) }\end{array}$ \\
\hline Sem & 0,168 & 0,021 \\
Com & 0,184 & 0,023 \\
\hline
\end{tabular}

Tabela 5. Média e desvio padrão.

Table 5. Average and standard deviation.

\begin{tabular}{lcc} 
Dispositivo & $\begin{array}{c}\text { Média } \\
(\%)\end{array}$ & $\begin{array}{c}\text { Desvio padrão } \\
\text { (minuto) }\end{array}$ \\
\hline Sem & 0,034 & 0,010 \\
Com & 0,040 & 0,011 \\
\hline
\end{tabular}

\section{CONCLUSÕES}

A falta de treinamento dos trabalhadores e de conscientização dos marceneiros e proprietários a respeito da segurança do indivíduo e do local de trabalho são os primeiros problemas a serem eliminados, para que se possa aproximar produtividade e bem-estar do trabalhador e, com isso, conseguir melhorar as atividades de ambas as partes, trabalhador e empregador.

A implantação de gaiolas nas áreas de risco das serras circulares e serras destopadeiras é vista como uma forma de minimizar os gargalos decorrentes da insegurança que estas máquinas oferecem ao operador.

A partir dos dados mostrados ao longo do trabalho, é possível comprovar a funcionalidade dos dispositivos e viabilizar sua instalação num processo de produção, a fim de criar uma concepção que favoreça sua utilização nas empresas que processam a madeira, principalmente em pequenas empresas, como aquelas encontradas no entorno de Jerônimo Monteiro-ES.

\section{AGRADECIMENTOS}

Ao Laboratório de Usinagem da Madeira da Universidade Federal do Espírito Santo (LUM/ UFES), ao funcionário Elecir, pela ajuda na fabricação dos dispositivos, e às empresas visitadas, que 
colaboraram com as entrevistas de seus funcionários e os testes com os dispositivos em suas serras.

\section{STATUS DA SUBMISSÃO}

Recebido: 22/12/2010

Aceito: 02/03/2011

Resumo publicado online: 15/03/2011

Artigo completo publicado: 31/03/2011

\section{AUTOR (ES) PARA CORRESPONDÊNCIA}

\section{Clovis Eduardo Nunes Hegedus}

Departamento de Engenharia Florestal, Universidade Federal do Espírito Santo - UFES, Av. Governador Lindemberg, 316, CEP 29550-000, Jerônimo Monteiro, ES, Brasil e-mail: hegedus@gerenco.com.br

\section{Rômulo Maziero}

Departamento de Engenharia Florestal, Universidade Federal do Espírito Santo - UFES, Av. Governador Lindemberg, 316, CEP 29550-000, Jerônimo Monteiro, ES, Brasil

e-mail: maziero.ufes@gmail.com

\section{REFERÊNCIAS}

Araújo CR, Salgado JC. Perfil dos trabalhadores que sofreram amputações no trabalho. Boletim Epidemiológico 2002; 5(16).
Brasil. Ministério do Trabalho e Emprego - MTE. Anuário estatístico de acidentes do trabalho: AEAT 2007. Brasília: TEM; 2008.

Carvalho J. Setor Madeireiro Lidera os Acidentes. Paraná Online, 19 jul. 2008. [cited 2010 jul. 20]. Available from: http://www.parana-online.com.br/ editoria/cidades/news/73844/?noticia=SETOR+MADE IREIRO+LIDEA+OS+ACIDENTES.

Carvalho DO, Silva F, Vieira JML, Cavalcante JWS, Rodrigues NE. Proteção de Máquinas em Marcenarias: ações Imprescindíveis para Prevenção de Acidentes. [monografia]. Jundiaí: Escola Técnica Estadual Vasco Antonio Venchiarutti; 2009.

Comissão Nacional de Classificação - CONCLA. Tabela CNAE 2.0 para consulta. Brasília: Secretaria da Fazenda; 2009. [cited 2009 maio 23]. Available from: http://www. receita.fazenda.gov.br/PessoaJuridica/CNAEfiscal/ cnaef.htm.

Debiasi H. Diagnóstico dos acidentes de trabalho e das condições de segurança na operação de conjuntos tratorizados [dissertação]. Santa Maria: Universidade Federal de Santa Maria; 2002.

Fiedler N, Venturoli F, Minetti LJ, Vale AT. Diagnóstico de fatores humanos e condições de trabalho em marcenarias no Distrito Federal. Revista Floresta 2001; 31(1-2): 105-113.

Silva RS, Souza AP, Minetti LJ. Avaliação do Perfil de Trabalhadores e das Condições de Trabalho em Marcenarias no Município de Viçosa - MG. Revista Árvore 2002; 26(6):769-775.

Souza TC. Prevenção dos Riscos Laborais nas Marcenarias e Carpintarias. DRT/SC - TEM; 2004. 